\title{
Leadership: Catalyst for Quality and Performance
}

Patricia Petryshen, RN, PhD

Editor, Practice

Canadian Journal of Nursing Leadership

T

he Canadian Journal of Nursing Leadership provides a unique opportunity to share ideas and information about innovations in healthcare, seeking new and improved ways of doing things. To stimulate thinking, Lynn Nagel, as editor-in-chief, asked the journal's editors to discuss their perspectives. Mike Villeneuve (2010) challenged us to share and debate innovations in policy, practice and leadership. Greta Cummings (2010) discussed new knowledge for better leadership and encouraged us to examine interventions to improve leadership and to transform practice. In this issue, I will examine the importance that innovation and leadership can play in improving quality and achieving performance excellence.

We are constantly reminded that a high quality of care and service delivery is a priority for healthcare organizations and governments. Discovering innovations, pursuing new approaches and interventions, and learning to do things differently are all at the heart of excellence. Everyone is expected to take personal responsibility for improving performance and to ask themselves: "Within the realm of my accountability, how can I do things differently to achieve the best possible outcomes for our patients, clients and residents?" This applies to all levels of an organization, from the board to senior management and the front-line care providers, as well as across multiple sites, networks and continuums of care.

In large, complex systems it can be challenging for leaders to create environments that embrace collaboration and innovation, and to support doing things differently through effective change management. However, high-performing organizations do just that: they develop a climate that fosters innovation at the front line and then embed this innovation into day-to-day practice. Fundamental to achieving and sustaining innovation is building structures that support and empower all employees to be creative and to take risks. 
For innovation to be embraced, organizations must provide oversight and governance for performance excellence, and create structures that have a mandate to improve quality of care and that support evidence-informed practice. Structures such as performance excellence committees and professional practice councils must have a direct reporting relationship to members of the senior executive, as well as accountability to the board of directors. Governing boards have the ultimate responsibility for organizational performance, which includes the organization's financial health, overall employee and physician competence, and quality of care in its many dimensions, such as patient-centredness, effectiveness, efficiency and safety.

We know that championing successful innovation requires a commitment from leaders and those who will be affected by the change, as well as strategy, teamwork, time and resources. We also know that doing things differently is challenging when faced with repeated restructuring, fiscal restraint, overall job loss and, particularly, the elimination of leadership positions in clinical care, professional practice and quality improvement.

Leaders send a powerful message when the perceptions of patients, clients and residents are clearly valued, and when this information is used to improve quality. We know that outcome data, when trended and compared to national benchmarks, has the greatest impact for accountability and practice. A familiar saying is "what gets measured generally gets done." This raises the question: Should we capture outcomes that are not easily measured, such as the impact of a new initiative, intervention or service? Nurses tell us that sometimes what is not measured can make the difference between "acceptable" and "exceptional" care.

Coming up with innovations is only half of the equation - embedding these changes into practice and policy is equally important. CJNL seeks articles on strategic leadership and policies to accelerate innovations in healthcare; innovations in clinical nursing practice; adoption and diffusion of innovations, and new approaches that support collaboration and knowledge exchange; and successful strategies for change management. We value the unique and broad perspective you can bring to this discussion as executives, chief nursing officers, practice leaders and clinical experts. We also welcome your expert assistance as manuscript reviewers. On behalf of CJNL, editor-in-chief Lynn Nagel, my co-editors Mike Villeneuve (policy) and Greta Cummings (research), and editorial director Dianne Foster Kent, we look forward to working with you.

\section{References}

Cummings, G. 2010. "New Knowledge and Evidence for Better Leadership." Canadian Journal of Nursing Leadership 23(3): 18-20.

Villeneuve, M. 2010. “Perspectives on Nursing Policy.” Canadian Journal of Nursing Leadership 23(2): 12-15. 